\title{
Seção de Revisão de Livros
}

Neste número da revista Pesquisa Operacional é apresentada a resenha do livro Análise de Séries Temporais, de Pedro Alberto Morettin e Clélia Maria de Castro Toloi. Os autores da resenha, Ana Paula Barbosa Sobral e Henrique Hippert, são doutores pelo Departamento de Engenharia Elétrica da PUC-Rio e atuam no Departamento de Estatística da Universidade Federal de Juiz de Fora como pesquisadora e professor adjunto, respectivamente.

Ronaldo Rocha Bastos

Departamento de Estatística / ICE

Universidade Federal de Juiz de Fora (UFJF)

Juiz de Fora - MG

rrbastos@estatistica.ufif.br

\begin{abstract}
Análise de Séries Temporais - Pedro Alberto Morettin, Clélia Maria de Castro Toloi, Editora Edgard Blücher Ltda, São Paulo, ISBN 85-212-0348-9, 2004, 535 pp., brochura. Informações: http://www.ime.usp.br/ pam
\end{abstract}

Este livro faz parte do Projeto Fisher, uma iniciativa da Associação Brasileira de Estatística que tem como finalidade publicar livros básicos de Estatística em língua portuguesa, para suprir a demanda dos professores dos cursos de bacharelado em Estatística por textos que possam ser adotados nas disciplinas que ministram.

A análise e previsão de séries temporais é uma das mais importantes áreas da Estatística, tanto no meio empresarial quanto no meio acadêmico, e provas disto são a procura cada vez maior por cursos na área (cursos de especialização e MBAs), a publicação de periódicos específicos (Journal of Forecasting, International Journal of Forecasting) e a realização de congressos e simpósios especializados na área (como a Escola de Séries Temporais, no Brasil, e o International Symposium on Forecasting). Contudo, a bibliografia em língua portuguesa sobre o assunto ainda é muito pequena, pelo que obras como esta são certamente bem-vindas.

Este livro é uma versão substancialmente revisada do texto anterior dos mesmos autores, "Previsões de Séries Temporais" (Atual Editora, 1987), com muito material novo acrescentado. Seis novos capítulos foram adicionados (Capítulos 11 a 16), além de uma grande quantidade de exemplos baseados em séries de dados reais. O material do livro foi dividido em 16 capítulos, dos quais os 10 primeiros são uma versão revisada do livro anterior.

Estes capítulos estão organizados como segue: 
Capítulo 1 - Preliminares

Capítulo 2 - Modelos para séries temporais

Capítulo 3 - Tendência e sazonalidade (modelos clássicos de decomposição de séries)

Capítulo 4 - Modelos de suavização exponencial

Capítulo 5 - Modelos ARIMA

Capítulo 6 - Identificação de modelos ARIMA

Capítulo 7 - Estimação de modelos ARIMA

Capítulo 8 - Diagnóstico de modelos ARIMA

Capítulo 9 - Previsão com modelos ARIMA

Capítulo 10 - Modelos sazonais

Capítulo 11 - Análise de intervenção

Capítulo 12 - Modelos não-lineares (especialmente os GARCH)

Capítulo 13 - Modelos de espaço de estados

Capítulo 14 - Análise de Fourier

Capítulo 15 - Análise espectral

Capítulo 16 - Modelos com memória longa (ARFIMA)

O Capítulo 1 inclui listas dos programas computacionais (SPlus e seu módulo S+FinMetrics, MINITAB, SCA, STAMP e EViews) e das séries temporais reais usadas ao longo do livro, além de duas seções introdutórias sobre séries econômicas e retornos financeiros. É interessante notar que o texto "Objetivos e Roteiros", que apresenta o plano do livro, não foi colocado na primeira seção, como seria de se esperar, mas sim na seção 1.9 , página 15 . O Capítulo 2 também inclui uma seção (2.8) sobre a distribuição de retornos financeiros, e outra (2.9) que trata das medidas de assimetria e curtose de variáveis aleatórias e talvez devesse ter sido incluída no Capítulo 1.

Em relação ao texto da edição anterior, alguns pontos que tratam dos modelos ARIMA foram aprofundados. Nesta nova edição foram incluídas, no Capítulo 6, discussões sobre os pressupostos dos modelos (normalidade e heterocedasticidade), o Teste de Dickey-Fuller (para identificar a ordem do $d$ ), os problemas causados pelo excesso de diferenciações da série, e as formas alternativas de identificação (métodos baseados em função penalizadora, FAC inversa e FAC estendida). Um dos capítulos novos sobre modelos ARIMA, contudo, parece estar mal localizado; o texto sobre modelos de memória longa (ARFIMA) deveria estar colocado no Capítulo 11, logo depois dos ARIMA sazonais, e não isolado no final do livro, no Capítulo 16.

Esta organização dos capítulos dá uma boa indicação das intenções dos autores e do públicoalvo pretendido. São dedicados, por exemplo, apenas um capítulo aos métodos de suavização, um aos modelos estruturais, e um aos modelos não-lineares; por outro lado, são dedicados sete capítulos aos modelos ARIMA. Além disso, não há capítulos específicos sobre a comparação e a implementação dos métodos de previsão, ou à análise dos erros de previsão. O livro aborda, prioritariamente, a análise das séries, mais do que a previsão, e se dirige em especial aos estudantes de Estatística ou áreas afins que tenham razoável base teórica em Matemática e Probabilidades. Isto é coerente com os objetivos do Projeto Fisher, no qual o livro se insere. Contudo, os próprios autores reconhecem que o conteúdo talvez seja excessivo para cursos de graduação. Nos "Roteiros de Utilização" do livro (p. xv), procuram indicar como o material poderia ser usado em cursos de diversas áreas. Para os cursos de graduação em Estatística, sugerem apenas os quatro capítulos introdutórios, junto com versões resumidas de nove dos capítulos restantes. O texto integral, segundo os autores, só seria indicado para cursos de pós-graduação em Estatística. 
Apesar da extensão, o livro é altamente recomendável. Abrange a maior parte dos tópicos da área de séries temporais (tanto no domínio do tempo, quanto no da freqüência), e mantém um equilíbrio razoável entre as exigências de rigor matemático e a facilidade de leitura. Além disso, é bem escrito, contém um grande número de exemplos ilustrativos baseados em dados reais (sem dúvida um dos aspectos mais atrativos da obra), está bem atualizado em termos de recursos de computação, inclui problemas ao final de cada capítulo, uma grande lista de referências no final do livro (há 18 páginas delas, muito bem escolhidas) e um índice remissivo, o que não é muito comum nas publicações brasileiras. Como pontos negativos, destacamos a necessidade de correção de alguns erros de impressão, tanto no texto quanto nas fórmulas, e talvez a necessidade de re-ordenação de algumas seções. O livro será com certeza de grande valia para os leitores que procuram um texto sério e atualizado em português como base para cursos sobre séries temporais.

Ana Paula Barbosa Sobral

Henrique Steinherz Hippert

Departamento de Estatística / ICE

Universidade Federal de Juiz de Fora (UFJF)

Juiz de Fora - MG 